\title{
An Interdisciplinary Facebook Incorporated STEM Education Strategy in Teaching and Learning of Dynamic Ecosystems
}

\author{
Noor Badari Khozali ${ }^{1}$, Mageswary Karpudewan ${ }^{1 *}$ \\ 1 Universiti Sains Malaysia, MALAYSIA
}

Received 8 May 2020 - Accepted 21 August 2020

\begin{abstract}
Ecology involves learning the multiple processes that occur in an ecosystem in a non-linear manner. For students to understand the complexity of an ecosystem and the processes, an interdisciplinary teaching and learning strategy is essential. Crossing the four disciplines that constitute STEM education, characterizes STEM education as an interdisciplinary approach. This study prescribes Facebook incorporated STEM education to conduct the lessons on a dynamic ecosystem, and the effects are reported. Mixed method research encompassing experimental research and qualitative interviews conducted with From Four students (equivalent to grade 9) revealed that the new strategy, Facebook incorporated STEM education fostered students understanding of ecosystems. The paired sample t-test analysis indicated significant differences between the pre and post understanding scores. The qualitative interview analysis informed how Facebook incorporated STEM education resulted in students acquiring better understandings. The study entails an interdisciplinary strategy is essential for effective teaching of a complex process such as the ecosystem.
\end{abstract}

Keywords: ecology, ecosystem dynamic, Facebook, interdisciplinary, STEM ducation

\section{INTRODUCTION}

Ecology, a vital concept embraced in the biology curriculum (Cetin, Ertepinar, \& Geban, 2015), aims to educate learners to handle nature in a more responsible manner (Yorek, Uğulu, Şahin, \& Doğan, 2010). Ecology is a multifaceted discipline as it involves learning about naturally occurring processes operating on multilevel with multiple non-linear interactions within the ecosystem (Jordan, Gray, Demeter, Lui, \& Hmelo-Silver, 2009). For this reason, the learners frequently viewed ecology as an abstract and challenging concept to understand. The lecture-based teacher-centered approach exacerbated the challenges encountered during the lessons on ecology (Pfundt \& Duit, 2002; Sander, Jelemenská, \& Kattmann, 2006). Literature in ecology education has recommended several strategies such as integration of technology and multimedia (Setiawan, Isnaeni, Budijantoro, \& Marianti, 2015), virtual laboratories (Haris \& Osman, 2015; Jussila \& Virtanen, 2014), forest exploration (Suprapto \& Supriatno, 2013), writing technique (Balgopal, Wallace,
\& Dahlberg, 2012) to facilitate learning about ecology. Despite the wide range of initiatives, difficulties in understanding concepts that constitute ecology prevail (Arkwright, 2014; Jussila \& Virtanen, 2014; Özata-Yücel \& Özkan, 2015; Purwanti \& Prihanta, 2016; Suprapto \& Supriatno, 2013). Student-centered teaching and teaching based on real-world phenomena are the common attributes of the strategies used in the past. The approaches result in students learning the processes in ecosystems in isolation. Crossing the boundaries of various disciplines is necessary for students to acquire a holistic understanding of the processes in an ecosystem (Lin \& Hu, 2003). The processes include energy flow and transfer between the livings and non-livings, food chain and food web, and the biotic and abiotic components. The science concepts that explain the ecosystems is made explicit when the concepts were taught and learn in association with real-world issues that are inherently interdisciplinary/multidisciplinary (Lin \& $\mathrm{Hu}, 2003$ ). However, the strategies employed to teach ecology in the past failed to explicitly embrace the interdisciplinary nature (Wyner \& Blatt, 2019). 


\section{Contribution to the literature}

- Ecology involves understanding the complex processes that occur in an ecosystem. The processes that embody an ecosystem are non-linear. Knowing and understanding the multifaceted processes requires interdisciplinary perspectives.

- This study introduces Facebook incorporated STEM education as an interdisciplinary strategy. The strategy bridges the gap in lacking an interdisciplinary approach for teaching and learning of the ecosystem.

- The study also informs using social networks such as Facebook to perform STEM education.

Integrated Science, Technology, Mathematics, and Engineering (STEM) education supported teaching concepts that require crossing the boundaries of STEM disciplines to accomplish understanding (English \& King, 2019). The frameworks suggested for practicing Integrated STEM education guided the crossing of boundaries between the STEM disciplines (Kelley \& Knowles, 2016; Moore, Stohlmann, Wang, Tank, Glancy \& Roehrig, 2014). Kelley and Knowles (2016) presented the four STEM disciplines as blocks and tackles with a rope threaded through the pulley system. Boundarycrossing happened when the rope representing the community of practice lifted the loads, the blocks and tackles, in solving the real-world problem. Kelley and Knowles (2016) grounded the function of the pulley system on situated learning theory. Moore et al., (2014) proposed the "Framework for STEM Integration in the Classroom" as a guide to performing Integrated STEM teaching. The framework depicts meaningful learning happens when students work in a team, collaboratively explore technology, and participate in engineering thinking to solve the problem. The fundamental knowledge of science and mathematics guides students' participation in exploring technology and engineering thinking. Positioning the learning on the situated learning paradigm Kelley and Knowles (2016) expressed the heightened role of the communication between the students and teachers to ensure successful boundary crossing of the STEM disciplines. Moore, Johnson, Peters-Burton, and Guzey (2016) emphasized teamwork and communication in ensuring students engage in exploring technology and participate in engineering thinking in solving a real-world problem. Both frameworks embrace the overarching feature for the need to have space for students to discuss and communicate ideas. The crossing of boundaries between STEM is embraced when the contentions are debated, discussed, and communicated to reach an agreement.

The advent of Web 2.0 has shaped human interaction and communication. The emergence of social networking sites (SNS), such as Facebook, Whatsapp, Instagram, Twitter, and We Chat as a consequence of significant development in Web-based applications, transformed the interaction and communication methods. The online platforms are favorable communication tools for youth, mainly secondary level schools' students for sharing information, opinions, and knowledge and to interact and communicate (Ford \& Ravansar, 2017). Social media is a convenient platform for exchanging knowledge and collaboration (Eid \& AlJabri, 2016). Facebook is the most ubiquitous and prominent social networking site, evidently promotes learning, offers a platform posting for comments, interacting and discussing the ideas with peers (Chen, Kuo, \& Hsieh, 2019). Staging the discussion on the Facebook platform mutually benefited both the educator and student (Prescott, Stodart, Becket \& Wilson, 2013a; Prescott, Wilson \& Becket, 2013b). A different study reported that Facebook enhanced the students' experience of discussing issues (Presscott et al., 2013a). Pai, McGinnis, Bryant, Cole, Kovacs, Stovall, and Lee (2017) asserted that extending the classroom discussion posting articles or videos on Facebook page engaged students to read, view, ask questions and provide their comments or opinions about the topic taught during a science lesson. The characteristics of STEM Education such as working in team, discussing and communicating ideas, developing arguments to solve problems directly parallel with the functions of the Facebook page that encourages debating to derive arguments in solving the problems.

A multidisciplinary learning context is essential to understand the multifaceted concept, such as ecology. The multidisciplinary nature of STEM Education is directly proportional to the multidisciplinary learning context necessary for understanding ecology. As an external tool for staging learning activities such as posting information, discussing, and communicating ideas, Facebook resembles collaborative discussion, communication skills, and teamwork highlighted in STEM education. Hence, this study introduces a pedagogical strategy that merges STEM education and Facebook (Facebook incorporated STEM Education) to teach the lessons on Ecology. The study aims at exploring the Form Four students' understanding of ecosystems following the lessons on Dynamic Ecosystems taught using Facebook incorporated STEM Education strategy. The study addresses several gaps found in the literature. Although the interdisciplinary approach is inevitable for understanding ecosystems, very few studies have documented using interdisciplinary approach to teach the lessons on ecology. The research on the outcome of 
STEM integration is limited (English, 2016). Only a few studies documented students' achievement in each STEM discipline at different grades (English, 2016). The findings of this study contributions to the lacking of information on the outcome of STEM Education about students' achievement in the science discipline.

\section{METHODS}

\section{Research Design}

The concurrent mixed-method research design was adopted to measure the effect of Facebook incorporated STEM education on students' understanding of Dynamic Ecosystem. For quantitative research, one group pretest-posttest design was employed. The pre and post-interview responses constitute qualitative research. Based on the concurrent mixed-method research guideline provided by Cresswell \& Plano Clark (2011), both quantitative and qualitative data were collected separately, and the findings were merged in describing the effectiveness of the treatment (Cresswell \& Plano Clark, 2011).

\section{Sample}

The study was conducted in the context of teaching and learning of Dynamic Ecosystems in Malaysia. Students begin secondary schooling in Malaysia at the age of 13 after completing six years of primary schooling. Students enroll in secondary school for five years, starting from Form One and complete secondary schooling at the age of 17 when they are in Form Five. The schooling years between Form One to Form Three is known as lower secondary and Form Four to Form Five is upper secondary education. During the lower secondary education, science is taught as general science. After completing lower secondary education, students decide for arts or science stream at the upper secondary level. For arts stream students, science is taught as general science. For science stream students' chemistry, physics and biology are taught as separate subjects. A total of 6416 -year-old Form Four (equivalent to grade 9) science stream students participated in this study. For the quantitative section of the study, all the 64 students answered the understanding test. For the qualitative interview, 10 students from the 64 students were purposively identified and interviewed. The students selected for the interviews consisted of high, mediocre, and low performers. The students were from two different classes from one school. The school represents the population of Form Four students in this country as the entire country adapts the same biology curriculum (Curriculum Development Division, 2012). The teaching and learning facilities of the participating school are generally like other government-funded schools in the country. The convenient sampling approach was used to identify the school, and the samples were assigned using an intact sampling approach as the researchers do not have the authority to neglect any students in the class. For the research, the lessons on Dynamic Ecosystems were conducted by a biology teacher with vast experiences in teaching secondary level biology. The teacher also has substantial experiences in STEM education.

\section{Research Instruments}

\section{Dynamic Ecosystem Understanding Test (DEUT)}

Students' understanding of ecosystem was measured using the Dynamic Ecosystem Understanding Test (DEUT). The DEUT consisted of 30 multiple-choice questions. The questions were obtained from previous years (2018-2017) secondary school leaving examination. School leaving examination is the evaluation that students sit at the end of the secondary level education. For biology, the topics thought at Form Four and Form Five levels are tested in the examination. The same question papers are answered by the students nationwide. The central examination board manages the examination. Experienced science teachers and educators set the questions for the examination. The questions are validated several times before the examinations. The 30 items in DEUT are grouped into four subscales: (a) components of biotic and abiotic in the environment (10 items), (b) colonization and succession processes in ecosystems (8 items), (c) population ecology (8 items), and (d) biological diversity (4 items). Each item was awarded 1 mark when the correct answer was provided. The maximum score for DEUT is 30 . This is possible when all the questions are answered correctly.

\section{Interviews}

As the study employs concurrent mixed-method design, qualitative interviews were performed to obtain insights into the quantitative findings on students' understanding of ecosystems. Interviews were conducted individually with the students. The interviews were conducted in two stages: before the treatment (week 1) and after the treatment (week 5) with each session lasting 15 to 20 minutes. The responses were recorded using a mobile phone, transcribed, and analyzed by the authors. The interview questions and the corresponding concepts are listed in Table 1.

\section{Research Procedure}

The research started with a pilot study to measure the instruments' reliability and validity and the validity of the treatment. For the pilot study, 60 Form Four students from a nearby school and three expert biology teachers participated. The Kuder -Richardson 20 (KR-20) value of 0.76 for the overall test implies the items are reliable. The biology teachers were in the opinion that the test items correspond with the content covered in the lessons on 
Table 1. Interview questions and the corresponding concepts

No Interview questions

1 What do you understand about components of an ecosystem? The importance of the ecosystem for survival and sustaining environmental balance?

2 Explain the two important processes taking place in new areas such as abandoned pools due to pioneer, successor, and dominant species gradually transformed this area to be more inhabited by other species and thus created a stable community known as climax communities.

3 How to determine the size and density of a population of moving and non-moving organisms in a given area?

4 What do you understand about the hierarchy of classification of organisms and the Linnaeus Binomial System used in the scientific naming system of organisms?
Concepts

Abiotic and biotic

component

Colonization and succession processes in ecosystems

Population ecology

Biological diversity
Dynamic Ecosystem. The items are plausible for the students' ability. The teachers were, in the opinion, the content covered by the Facebook incorporated STEM education parallel with the objectives of the lessons presented in the syllabus, and interview questions correspond to the treatment.

The actual research was conducted for 7 weeks. In week 1, baseline measurement (pretest) was performed to gauge the students' prior knowledge on Dynamic Ecosystem using Dynamic Ecosystem Understanding Test (DEUT). The interviews were conducted to obtained insights into their prior knowledge. In week 1 , the teacher ensured that all the participating students have a Facebook account and access to the Facebook either through mobile phone other digital devices. A Facebook group with students and the teacher as members was created for purpose of the study. The messages posted on the Facebook wall is available for the members' viewing. In week 2 , lesson plans prepared by the researchers were shared with the teacher. The teacher was briefed on the lesson plans, and guidance was provided to execute the STEM teaching following the plans. As the teacher already has some knowledge of STEM education, she could easily grasp the lesson plans' information. Additional emphasis was given in explaining and guiding the teacher on creating a discussion on the Facebook page. In week 3 to week 5, the five lessons on Dynamic Ecosystems were conducted using Facebook incorporated STEM teaching. The topic understanding the role of biotic and abiotic within the ecosystem is included in lesson 1, lesson 2 covers the colonization and succession processes in unused and abandoned mining pool, lessons 3 and 4 introduces to random sampling technique and estimation of population sizes of organisms in a specific area and in lesson 5 taxonomy of living things were taught.

The lessons started with the teacher posing questions and information on her Facebook page. For lesson 1, questions such as 'What is ecological colonization? What is ecological succession? and What occurs during ecological succession?' were posted. Students were also requested to design a terrarium model representing an unused and abandoned pool. Students worked in small groups relating the answers in designing the model. The information obtained from the discussion that took place on the Facebook page was later applied while developing the model for real during the laboratory activity. During the laboratory session, materials and apparatus such as plastic aquarium containers, petri dishes/bowls, pebbles, soil, tap water, spray bottles, grass seeds, mustard seeds, flower seeds, submerged plant (Elodea sp), floating plant (Lemna sp), guppy fish, snails, crickets, and worm were provided.

Guided by information on designing the model from the Facebook discussion, students developed the model using the materials provided by the teacher. Any changes to the model were observed, recorded, and discussed with the group members to provide an overview of the colonization and displacement. The development of the model was videotaped using a mobile phone and uploaded onto the Facebook page. Teacher posted instruction on her Facebook page to guide the students to create the discussion. All the groups were asked to watch the videos posted. Videos shared showed a picture of colonization and displacement processes. In groups, students commented on the model developed and provided suggestions to improve the model. Besides that, each group was asked to propose at least one question related to the task that they have prepared to trigger the discussion. An active engagement took place where each group provided ideas about colonization and displacement. This again provided students an overview of the colonization and displacement process and helped them better understand the terms such as pioneer, successor, dominant species, and climax community.

The four STEM disciplines were reflected during the lesson on colonization and succession. The knowledge on colonization and succession process constitutes the science discipline; deciding the appropriate thickness of pebbles and layers of soil, recording the growth, and the watering process depicts the mathematic disciplines; while developing the terrarium model, students explored various technology simultaneously participated in engineering thinking in designing the prototype. Staging the information on Facebook pages facilitated the learning. The Facebook platform created a room for productive discussion and communication. During discussions, the four STEM disciplines were reemphasized. Similarly, the four STEM disciplines were 
Table 2. Thematic analysis of the interview responses

\begin{tabular}{|c|c|}
\hline Interview questions & Code \\
\hline $\begin{array}{l}\text { What do you understand } \\
\text { about components of an } \\
\text { ecosystem? The } \\
\text { importance of the } \\
\text { ecosystem for survival } \\
\text { and sustaining } \\
\text { environmental balance? }\end{array}$ & $\begin{array}{l}\text { S1..biotic component refers to living organisms such as } \\
\text { plants like Elodea sp ...ermm... and animals like fish. } \\
\text { crickets and worms and abiotic components refer to } \\
\text { non-living components such as temperature, air, light } \\
\text { intensity, and mineral likes pebbles. The components } \\
\text { are related as abiotic factors influence the distribution } \\
\text { of organisms and enable food and mate competition to } \\
\text { occur for the survival of the species..ermmm any } \\
\text { changes to the component affects the entire ecosystem. }\end{array}$ \\
\hline
\end{tabular}

Explain the two S2...n no species was seen growing on the surface of the - pioneer species

important processes terrarium model in days 1 and 2. However, on day 3, -successor species

taking place in new areas, grass seedlings started to grow......this shows the -dominant species

such as abandoned pools, colonization process happened. The grass represents the - climax community

due to pioneer, successor, pioneer species. The pioneer species gradually change

and dominant species and adapt to the new species. On day 8, the mustard

that gradually

seed had grown and began to dominate the grass

transformed that area species. The succession process took place. The mustard

into more inhabited by plant represents a successor species. The same processes

other species and become continue. On the 14th day, flower seed dominates and

a stable community

known as climax

communities.

is now called as dominant species. Over time the

terrarium model had turned into a bush and is in stable

condition and creates a climax community."

How to determine the size and density of a population of moving and non-moving organisms in a given area?'

\section{S5...There is two technique...quadrat sampling} technique and capture, mark, release, and recapture technique. The quadrat sampling technique is appropriate for determining the percentage coverage, frequency, and density of the species in the study area usually performed on non-moving organisms such as the population of Mimosa pudica found in school fields. While the capture, mark, release, and recapture technique is appropriate to determine the population size of moving organisms such as woodlice under the tree.

What do you understand about the hierarchy of classification of organisms and the Linnaeus Binomial System used in the scientific naming system of organisms?'

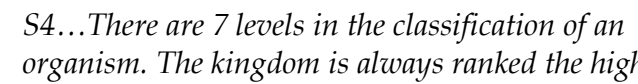

followed by division, class, order, family, genus, and species. Linnaeus Binomial System used to provide scientific names for the organism. For example, Tiger is presented as Panthera tigris in which 'Panthera' represents the genus, and 'tigris' represents a particular species."
Category (producer, primary consumer, secondary consumer and tertiary consumer)

-interaction between abiotic and biotic component for

environmental balance

(a)

-the quadrat sampling technique Population (determine the density, frequency ecology and percentage coverage of the species)

- the capture-mark-release

recapture method

(estimate the population size of an organism in a habitat)

-8 major taxonomic ranks Biological (domain, kingdom, phylum, class, diversity order, family, genus, and species) -example: Tiger is presented as Panthera tigris. 'Panthera' represents the genus and 'tigris' represents a particular species

SI-student 1, S2-student 2, S5-student 5 and S4-student 4

also reflected in the rest of the lessons. Across the five lessons, participating in engineering designing and thinking while exploring technology in producing the prototypes such as closed ecosystem bottle in lesson 1; terrarium model in lesson 2; prototype on quadrat in lesson 3, a model describing grasshopper populations in lesson 4 and taxonomy and classification chart in lesson 5 mirrors the engineering and technology disciplines. Mathematical knowledge is instrumental in recording the growth, deciding the thickness, creating formulas, and documenting and presenting the data in tables and graphs. Staging the aggregate information from the four disciplines in solving the problems on the Facebook page facilitated discussion and communication of ideas in making an informed decision concerning the issue.

\section{Data Analysis}

A paired sample t-test was performed on the quantitative data. The transcribed interview responses were analyzed according to thematic analysis framework proposed by Braun and Clarke (2006). Thematic analysis was performed independently by three biology teachers. The analysis began with teachers going through the transcript for multiple times. The next step was to group the codes into categories representing each concept tested in this study. In ensuring the codes correspond with the categories, many cycles of reviews were performed. Table 2 presents the categories derived from the codes for each concept. 
Table 3. Mean scores and standard deviation values

\begin{tabular}{lcccc}
\hline Test & Max & Min & Mean & Std deviation \\
\hline Pre-test & 7.00 & 15.00 & 12.70 & 4.622 \\
Post-test & 12.00 & 25.00 & 20.48 & 3.122 \\
\hline
\end{tabular}

Table 4. Comparison of interview responses on components of biotic and abiotic in the environment from the first interview and second interview

\begin{tabular}{|c|c|c|}
\hline Student & 1st interview & 2nd interview \\
\hline$\overline{\text { S1 }}$ & $\begin{array}{l}\text { Abiotic refers to non-living physical and chemical } \\
\text { elements in the ecosystem, such as water, air, soil, } \\
\text { and sunlight.... Biotic factors are living organisms } \\
\text { such as guppy fish..snail...crickets.. and also plant- } \\
\text { like Elodea sp...mustard plant. Both components } \\
\text { are equally important for feeding and competition } \\
\text { to survival. }\end{array}$ & $\begin{array}{l}\text { Living organism interacts with other living and non-living things to stay } \\
\text { alive. Green plants such as Elodea species and grass are producers making } \\
\text { their food by using energy from the sunlight, water, and carbon dioxide to } \\
\text { carry out photosynthesis. Other organisms, such as guppy fish, crickets, } \\
\text { worm, and snail, are the consumers. They cannot make their food, so they } \\
\text { get their energy by eating on other organisms. The flow of energy from the } \\
\text { sun to different organisms in an ecosystem supports the life process of } \\
\text { living organisms. The models presented during our discussion on the } \\
\text { Facebook page enabled us to view the connections between the biotic and } \\
\text { abiotic components. }\end{array}$ \\
\hline S3 & $\begin{array}{l}\text { There are two components of an ecosystem.... } \\
\text { abiotic component and second is the biotic } \\
\text { component. Abiotic components are non-living } \\
\text { chemical and physical parts of the environment, } \\
\text { such as water, air, sunlight, and temperature...that } \\
\text { affects living organisms and the functioning of the } \\
\text { ecosystem. While biotic components are living } \\
\text { components like guppy fish, worm, snail, aquatic } \\
\text { plant, and mustard plant that affect another } \\
\text { organism or shapes the ecosystem. }\end{array}$ & $\begin{array}{l}\text { The interaction between two components is important in supporting the life } \\
\text { processes of living organisms. The plant requires a specific temperature, } \\
\text { moisture, and soil. Animals rely on those plants for their food. Anything } \\
\text { that affects the ecosystem disturbs the balance and force the organisms to } \\
\text { adapt to the changes. For example, fluctuation in Carbon dioxide gasses } \\
\text { may disturb the numbers of Elodea species in the model, increasing the } \\
\text { competition between the fish. The terrestrial ecosystem at the top of the } \\
\text { model is disturbed due to lacking Carbon dioxide gases. Discussing the } \\
\text { terrestrial model on Facebook allowed us to visualize the entire ecosystem of } \\
\text { the model. }\end{array}$ \\
\hline
\end{tabular}

S1-student 1, S3-student 3

\section{RESULTS}

\section{Quantitative Analysis}

Before the t-test analysis, normality check was performed on the pre and post-test data. The Skewness and Kurtosis values ranging from -2 to +2 depict that the data is normally distributed (George \& Mallery, 2010). The analysis of the responses provided for DEUT shows that the students obtained a higher mean score for the post-test $(M=20.48 ; S D=3.12)$ compare to the pre-test $(\mathrm{M}=12.70 ; \mathrm{SD}=4.62)$ as presented in Table 3. The maximum possible score when all the questions were correctly answered is 30 . Both the minimum and maximum scores obtained in the post-test are higher than the pre-test. The paired sample t-test findings revealed that the mean scores' differences are statistically significant $(p<000 ; t=9.74)$. The findings imply that the Facebook incorporated STEM Education strategy resulted in the differences and is the possible reason explaining the higher post scores.

\section{Qualitative Interview Findings}

Components of biotic and abiotic in the environment. Questions 'what do you understand about an ecosystem's components?' and 'describe the importance of the ecosystem for survival and sustaining environmental balance?' were asked during the first and second interviews to assess students' understanding of biotic and abiotic components in the environment and its importance. In the first interview, all 10 students stated an ecosystem consisting of both biotic and abiotic components. Among the 10 students, seven provided almost similar responses stating that the components are dependent on each other. The remaining three students unable to define the components correctly. In the second interview, all the 10 students provided various reasons describing the relationship between biotic and abiotic components. Referring to specific examples, S1, claimed that the abiotic factors influence the distribution of biotic factors. In contrast, S3 mentioned that any fluctuation in the abiotic factors disturbs the ecosystem's balance. S3, in his responses, referred to $\mathrm{CO}_{2}$ gas as the biotic component and explained how it affects other livings in the terrestrial ecosystem. In Table 4, interview responses obtained from S1and S3 were presented.

Comparing the responses provided by S1 and S3 in the first and second interviews, both students exhibited explicit capability in describing the two components and the importance of the components in sustaining the balance of the ecosystem. The questions posed at the initial stage of teaching focused on the students' thinking towards planning to design a terrestrial model and execute the planning in developing the model. Subsequently, a discussion about the model on the Facebook page enabled them to visualize the interconnection between the components. 
Table 5. Comparison of interview responses on colonization and succession processes in ecosystems from the first interview and second interview

\begin{tabular}{lll}
\hline Student & 1st interview & 2nd interview \\
\hline S4 & The processes are colonization and succession. & ...........terrarium model represents the bare land where there is an abandoned \\
& The colonization happens first, followed by & pool. Despite the lack of nutrients, some organisms occupy the area. For example, \\
succession. & Elodea species is the first submerged species grew in the abandoned pool and \\
& represented a pioneer species in the terrarium model because of its have special \\
& adaptive features to survive in unfavorable condition such as long fibrous roots \\
& that penetrate deep into the soil of harsh environments to absorb nutrients and \\
& hold the sand together. This process is known as colonization.........
\end{tabular}

Colonization and succession are two important ...the presence of Elodea species (pioneer species) gradually changes the processes that take place in new areas. There are condition of the abandoned pool, making it no longer suitable for itself but more several species involves during this process that suitable for floating plants such as Lemna species (successor species). Gradually, occurs, such as pioneer species, successor species, dominant species, and climax community.

S8 Two processes that occur in new areas such as an abandoned pool before it becomes more suitable for other species to inhabit are colonization and succession.

\begin{abstract}
Lemna species (successor species) replaces Elodea species (pioneer species) in the
\end{abstract} abandoned pool. This process is called the succession process.

the succession process occurs continuously in the terrarium model where the floating plant (Lemna species) gradually changes the condition of the abandoned pool by adding humus from decaying leave and make the soil condition now more fertile and suitable for other plants (grass). The succession process goes on. The pond became shallow as the dead grasses deposits as organic matter. The pond dries off as the water evaporates and makes way for another terrestrial plant such as a mustard plant (herbaceous plant) to grow. Later, flower plants (woody plants) begin to grow, and gradually the terrarium filled with a bushy. At this stage, the model represents a tropical rainforest where this condition shows that a climax community is formed, and the process of succession will stop.

S4-student 4, S5-student 5 and S8-student 8

Colonization and succession processes in an ecosystem. The question 'explain the two processes that take place in abandoned pools for the pioneer, successor and dominant species gradually transform the area for other species to inhabit to create a stable community known as climax communities' was posed during the first and the second interview to assess the students' understanding of colonization and succession processes. For this question, all the students can name the two processes without able to explain the processes. Out of the ten students, eight students said colonization would take place first, followed by succession. In the second interview, 10 students provided elaborated illustration about the two processes taking place in the terrarium model of an abandoned pool that they have created. For instance, in the second interview, S4 thought Elodea sp is the first species grow in the abandoned pool representing pioneer species in the terrarium model because of its adaptive features such as long fibrous roots that penetrate deep into the soil of harsh environments to absorb nutrients and hold the sand together. S5 said that the presence of Elodea sp (pioneer species) gradually made the pond shallower for floating plants such as Lemnasp (successor species) to grow. This process is known as a succession process. Another student, S8, said that the succession process occurs continuously in the terrarium model whereby grasses (amphibious plant), mustards (herbaceous plant), and flower plants (woody plant) replaces each other gradually to form a thick tropical rainforest. At this stage, the succession process is about to complete, and the model almost reaches the climax community. The responses of S4, S5, and S8 obtained in the first and second interviews were compared and illustrated in Table 5.

In the second interview, $\mathrm{S} 4, \mathrm{~S} 5$, and $\mathrm{S} 8$ provided a complete description of colonization and succession, referring to the terrestrial model that they have developed. The experiences gained from designing the model and observing the processes in the model embarked on students exploring a real-life incident. Discussing the activity using the Facebook platform enabled students to consider complex views in proposing ideas and solutions concerning real-life incidents. Considerably evaluating the complex multidimensional ideas resulted in building an abandoned pool ecosystem controlling the biotic and abiotic components that influence the colonization and displacement processes in the ecosystem. Posting the model on the Facebook platform permitted students to evaluate the model further simultaneously developed ideas about colonization and displacement.

The population of an ecology. The question 'how to determine the size and density of a population of organisms in a given area?' was asked to gauge students' knowledge of measuring the population. For this question, during the first interview, students asserted two common techniques capture, mark, release, and recapture method, and quadrat sampling technique. During the second interview, students appeared to be more knowledgeable about both techniques and methods. Furthermore, the students applied correct 
Table 6. Comparison of interview responses on the population of ecology from the first interview and second interview Student 1st interview 2nd interview

\begin{tabular}{|c|c|c|}
\hline S6 & $\begin{array}{l}\text { The size and density of a population of an } \\
\text { organism in a given area are determined } \\
\text { using the capture, mark, release and } \\
\text { recapture method and the quadrat } \\
\text { sampling technique. }\end{array}$ & $\begin{array}{l}\text {.....the quadrat sampling technique is mainly used to determine the distribution of } \\
\text { plants like Mimosa pudica. Chrysopogon aciculatus and Erichloa procera whereby we } \\
\text { apply the formula given to determine the density, frequency, and percentage coverage } \\
\text { of all the species found in the school field. We then determined the most dominant } \\
\text { species on the field is Mimosa pudica. Meanwhile, to estimate the population size of } \\
\text { animals that move freely, such as grasshopper, the capture, mark, release, and } \\
\text { recapture method is used. The Facebook discussion created a realistic context for } \\
\text { applying the method differently. }\end{array}$ \\
\hline St & $\begin{array}{l}\text { There are two ways to determine the size } \\
\text { and density of a population of an } \\
\text { organism in a given area. First is the } \\
\text { capture, mark, release, and recapture } \\
\text { method, and the second is through a } \\
\text { quadrat sampling technique. }\end{array}$ & $\begin{array}{l}\text {........... The activity of field study using a quadratic sampling technique gives me } \\
\text { experience like an engineer. I have been involved in building a quadrat, a squares frame } \\
\text { made of wood used as a tool in activities of quadrat sampling technique. Besides that, I } \\
\text { also involved designing a model of grasshopper populations in grassland habitat using } \\
\text { beads in the activities of capture, mark, release, and recapture method. The fun of } \\
\text { discussing and comparing the models on Facebook urged exploring the use of the } \\
\text { quadratic sampling technique. }\end{array}$ \\
\hline
\end{tabular}

S6-student 6, S7-student 7

Table 7. Comparison of interview responses on biological diversity from the first interview and second interview

\begin{tabular}{|c|c|}
\hline Student & 1st interview \\
\hline S1 & $\begin{array}{l}\text { In my opinion, the hierarchy of } \\
\text { classification of organisms and the } \\
\text { Linnaeus Binomial System is used to } \\
\text { classify organisms into smaller groups to } \\
\text { facilitate identifying, describing, and } \\
\text { naming of the organism. }\end{array}$ \\
\hline
\end{tabular}
2nd interview

After getting involved in the activities of designing a candy taxonomy chart, I understood that hierarchy of classification is the process of arranging various organisms into successive levels of the biological classification either in that a decreasing or an increasing order from kingdom to species and vice versa. Each this level of the hierarchy is called the taxonomic category or rank. In this classification system, the kingdom is always ranked the highest, followed by phylum, class, order, family, genus, and species. I learned how to use the Linnaeus Binomial System in writing the scientific name of an organism correctly through activities of making biotic classification foldable. Each species is given a name that consists of two parts. The first part is the Genus to which the species belongs, and the second part is the species' name.

I think the hierarchy in the classification of the organism is a system used by scientists to classifying living organisms, and the Linnaeus Binomial System is a system used to name the species.
The hierarchy in the classification of organisms enables living organisms to be classified according to certain basic features based on the seven-level of the hierarchical taxonomic category, either decreasing or increasing order from kingdom followed by phylum, class, order, family, genus, and species or vice versa. While the Linnaeus Binomial System is the binomial naming system was first uniformly. This system uses two words to name every species of organism found. The first word in the name refers to the genus and should be written in uppercase, and the second word is the species name must be written in lower case.

S1-student 1, S8-student 8

formulas to determine the density of the population of Mimosa pudica $s p$ and population size of grasshopper (bead) in the study area. In Table 6, excerpts of the interview responses of $\mathrm{S} 6$ and $\mathrm{S} 7$ are presented.

In the second interview, S6 and S7 provided a complete description of the technique and methods used to determine the size and density of organisms in a given area. The Facebook Incorporated STEM activity provided students with a realistic and fun context of exploring the ecosystems. Students participated in engineering thinking in designing a quadrat and built a model of grasshopper populations. Mathematical skills were involved in recording data into tables, moving data into formulas in solving related problems. Active participation in the activity provided students with an opportunity to view both quadrat sampling techniques and capture mark release and recapture methods.

Biological diversity. The questions 'what do you understand about the hierarchy of classification of organisms' and 'explaining the use of Linnaeus Binomial System to scientifically name the organism' were asked during the first and second interviews to assess students' understanding of biological biodiversity. In the first interview, all the students said that the Linnaeus Binomial System is used for classifying organisms into smaller groups to facilitate identification, description, and naming. In the second interview, all the students appeared more knowledgeable about the classification system. The students were able to apply the seven levels of classifications of organisms that they learned from the activity on designing a candy taxonomy chart. Furthermore, students used the Linnaeus Binomial System in writing the scientific name of an organism correctly after taking part in the activity of making the biotic classification folder. In Table 7, excerpts of the interview responses of $\mathrm{S} 1$ and $\mathrm{S} 8$ are presented.

In the second interview, S1 and S8 provided a complete description of the seven hierarchical 
classifications of organisms and the use of Linnaeus Binomial System for naming the organisms scientifically. The Facebook platform's use has provided an inquirybased learning space that allowed students to share learning ideas with peers and teachers to visualize the hierarchy through demonstrations of the candy taxonomy chart. Meanwhile, watching videos shared by the teacher on the Facebook page provided students with ideas for designing a biotic classification folder. Practical exposure in developing the candy taxonomy chart and biotic classification folder helped to understand the seven taxonomic categories or ranks: the kingdom, phylum, class, order, family, genus, and species.

\section{DISCUSSION AND CONCLUSION}

In biology education, understanding Dynamic Ecosystem is imperative to handle nature responsibly. However, students viewed ecology as an abstract concept as it involves learning multiple processes that occur in a system (Cetin et al., 2015; Eilam, 2002; Sterman \& Sweeney, 2007). Students frequently encounter difficulties in learning the complex, multifaceted concept. The challenges subsequently led to the development of misconceptions (Eilam, 2002; Griffiths \& Grant, 1985; Jussila \& Virtanen, 2014; Munson, 1994; Sterman \& Sweeney, 2007). Literature in ecology strongly believed that teaching the processes in a compartmentalized manner accounts for students facing difficulty in understanding the concept (Waheed \& Lucas, 1992). Evidence is available from the studies conducted by Lin and $\mathrm{Hu}$ (2003), and Kinchin (2010) that students understood the processes in ecosystems distinctively, and relationships between the processes were vaguely understood. For this reason, several attempts to improve understanding about ecology unable to produce results as expected. The recommended approaches did not explicitly present the processes in the ecosystems in an interconnected manner (Jordan et al., 2014).

Interconnections between the concepts emerged when the real-world experiences of the ecosystem are provided. In the real-world ecosystem exists in associations with multiple disciplines. The notion existing strategies failed to reflect the interconnection between the processes created a room to introduce an interdisciplinary teaching strategy. In other words, the interdisciplinary strategy necessitates students to cross boundaries between the disciplines while learning about ecology. The multidisciplinary approach that is gaining incremental attention is Integrated STEM education (English \& King, 2019). Integrated STEM education derived various positive learning outcomes when the strategy is practiced using varied platforms. For instance, lab-based STEM education improved students' understanding of electrolysis (Huri \& Karpudewan, 2019), problem-based STEM (English, King, \& Smeed,
2017), and project-based STEM (Han, Rosli, Capraro, \& Capraro, 2016; Lou et al., 2017) improved students' learning. The positive outcomes derived from the students' active engagement, considering the four STEM disciplines in solving the real-world problem. The interdisciplinary characteristic of STEM education corresponds to Eilam's (2002) call to transform the domination of single disciplinary education to multidisciplinary to necessitate learning ecology from multifaceted perspectives. Contradicting to other studies, in this study, STEM Education was integrated with Facebook as a platform to stage the discussion.

The study reports on the effectiveness of using Facebook incorporated STEM education in teaching and learning the lessons on dynamic ecosystems. The quantitative paired sample t-test revealed significant differences between the pre and posttest mean scores. The qualitative findings provided insightful details on students' understanding of Dynamic Ecosystem, which constitutes abiotic and biotic components, colonization and succession process, population ecology, and biological diversity of an ecosystem. The findings of the current study contradict with several other studies which have documented students' problem explaining the relationships among the populations in a food network (Eilam, 2012; Lin \& Hu, 2003; Ozkan, Tekkaya \& Geban, 2004; Reiner \& Eilam 2001); roles of each organism involved at every level of the trophic in the food chain and the role of producers, consumers, and decomposers (Özata-Yücel \& Özkan, 2015). Crossing the boundaries between the four STEM disciplines and discussing the ideas and posting the views on the Facebook page compelled into exploring the problem from a broader perspective to gain a better understanding of the concepts. The study is informative for teachers and science educators engaged in teaching STEM education. Facebook incorporated STEM education addresses the frequent challenge that STEM teaching required significant reshuffling of the curriculum. The Facebook incorporated STEM education is a feasible approach for teachers and educators to adopt as the approach denotes a list of activities that the students could perform during the lessons on ecology. The findings are parallel with other STEM education initiatives (Chen \& Chang, 2018; Kuenzi, 2008; Park, Park, \& Bates, 2018; Shahali, Halim, Rasul, Osman, \& Zulkifeli, 2016) which documented the effectiveness of STEM integration in learning science concepts. The findings also echo other studies which have used Facebook as an educational tool (Aaen \& Dalsgaard, 2016; Camus et al., 2016; Chen, 2015; O'Bannon, Beard, \& Britt, 2013) to facilitate discussions and improve learning.

The interdisciplinary nature of Facebook incorporated STEM education explains the understanding experienced by the students. All the five lessons performed during the treatment necessitated the 
students to participate collaboratively in engineering design, exploring the technology in solving the realworld problem. The knowledge of science and mathematics guided engineering thinking in all the lessons. Posting information on the Facebook page before and after the real lesson created a platform for discussing the topic. The discussion before the lesson, on the Facebook, prepared the students for the learning in a real lesson (Dyson, Vickers, Turtle, Cowan, \& Tassone, 2015) and posting after the lesson extended learning as students actively engaged in discussions. During both discussions, crossing between disciplines was further reflected. The characteristics of boundary-crossing notable in Facebook incorporated STEM education mirrors the (Kelley \& Knowles, 2016) explanation of Integrated STEM education using the pulley system whereby the blocks and tackle representing the four STEM disciplines were pulled using a rope serving the community of practice in solving the real-world problem. The Facebook incorporated STEM education also echoes the elements proposed by Moore et al. (2014) in the "Framework for STEM Integration in the Classroom". Students collaboratively engaged in exploring technology, participated in engineering thinking to solve the problem. The fundamental knowledge of science and mathematics guided in exploring the technology and participating in engineering thinking.

Despite using a mixed-methods approach in reporting the effectiveness of the treatment, the study exhibits several limitations. For the quantitative research, type one errors are committed while performing the paired sample t-test analysis. For qualitative research, a small number of students were interviewed. According to Creswell and Plank (2017), paired sample t-test and smaller sample size for an interview are possible to report the effectiveness of any treatment. However, to improve the generalization of the findings, the study needs to be repeated, perhaps using multivariate analysis for the quantitative research reporting the sub-constructs of dynamic ecosystems and engage more students in the interviews in the future.

\section{REFERENCES}

Aaen, J., \& Dalsgaard, C. (2016). Student Facebook groups as a third space: between social life and schoolwork. Learning, Media and Technology, 41(1), 160-186.

https:/ / doi.org/10.1080/17439884.2015.1111241

Arkwright, A. B. (2014). Fourth and eighth grade students' conceptions of energy flow through ecosystems (Unpublished PhD dissertation). University of Kentucky, USA.Retrivedfrom http:/ / uknowledge.uky.edu/cgi/viewcontent.cgi ?article $=1002 \&$ context $=$ edsc_etds
Balgopal, M. M., Wallace, A. M., \& Dahlberg, S. (2012). Writing to learn ecology: a study of three populations of college students. Environmental Education Research, 18(1), 67-90. https: / / doi.org/10.1080/13504622.2011.576316

Braun, V., \& Clarke, V. (2006). Using thematic analysis in psychology. Qualitative Research in Psychology, 3(2), 77-101.

https:/ / doi.org/10.1191/1478088706qp063oa

Camus, M., Hurt, N. E., Larson, L. R., \& Prevost, L. (2016). Facebook as an Online Teaching Tool: Effects on Student Participation, Learning, and Overall Course Performance. College Teaching, 64(2), 84-94. https://doi.org/10.1080/87567555. 2015.1099093

Çetin, G., Ertepinar, H., \& Geban, Ö. (2015). Effects of conceptual change text based instruction on ecology, attitudes toward biology and environment. Educational Research and Reviews, 10(3), 259-273. https://doi.org/10.5897/ ERR2014.2038

Chen, S. Y., Kuo, H. Y., \& Hsieh, T. C. (2019). New literacy practice in a Facebook group: The case of a residential learning community. Computers $\mathcal{E}$ Education, 134, 119-131. https://doi.org/10.1016/ j.compedu.2019.01.008

Chen, Y. C. (2015). Linking learning styles and learning on mobile Facebook. International Review of Research in Open and Distance Learning, 16(2), 94-114. https://doi.org/10.19173/irrodl.v16i2.2038

Chen, Y., \& Chang, C. C. (2018). The Impact of an Integrated Robotics STEM Course with a Sailboat Topic on High School Students' Perceptions of Integrative STEM, Interest, and Career Orientation. Eurasia Journal of Mathematics, Science and Technology Education, 14(12), 1614. https:/ / doi.org/10.29333/ ejmste/94314

Creswell, J. W., \& Plano Clark, V. L. (2011). The nature of mixed methods research. Designing and conducting mixed method research. 2nd ed. London: Sage Publications, 1-18.

Creswell, J. W., \& Plano Clark, V. L. (2017). Designing and conducting mixed methods research. Sage publications.

Curriculum Development Division. (2012). Biology Form Four Curriculum Specifications: Integrated Curriculum for Secondary Schools. Putrajaya: Ministry of Education Malaysia.

Dyson, B., Vickers, K., Turtle, J., Cowan, S., \& Tassone, A. (2015). Evaluating the use of Facebook to increase student engagement and understanding in lecture-based classes. Higher Education, 69(2), 303 313. https:/ / doi.org/10.1007/s10734-014-9776-3

Eid, M. I., \& Al-Jabri, I. M. (2016). Social networking, knowledge sharing, and student learning: The case 
of university students. Computers $\mathcal{E}$ Education, 99, 14-27.

https:// doi.org/10.1016/j.compedu.2016.04.007

Eilam, B. (2002). Strata of comprehending ecology: Looking through the prism of feeding relations. Science Education, 86(5), 645-671. https://doi.org/ $10.1002 /$ sce. 10041

Eilam, B. (2012). System thinking and feeding relations: Learning with a live ecosystem model. Instructional Science, 40(2), 213-239. https://doi.org/10.1007/ s11251-011-9175-4

English, L. D. (2016). STEM education K-12: Perspectives on integration. International Journal of STEM Education, 3(1), 3. https:// doi.org/10.1186/s40594016-0036-1

English, L. D., \& King, D. (2019). STEM integration in sixth grade: designing and constructing paper bridges. International Journal of Science and Mathematics Education, 17(5), 863-884. https://doi.org/10.1007/s10763-018-9912-0

English, L. D., King, D., \& Smeed, J. (2017). Advancing integrated STEM learning through engineering design: Sixth-grade students' design and construction of earthquake resistant buildings. Journal of Educational Research, 110(3), 255-271. https:// doi.org/10.1080/00220671.2016.1264053

Ford, R. \& Ravansar, H. (2017) CPD 12 Impact Skills 3Social Media for Academics: Research Dissemination. Retrieved from http://www.staff net.manchester.ac.uk/employment/training/pers onal-development/academicstaff/

George, D., \& Mallery, P. (2010). SPSS for Windows step by step. A simple study guide and reference (10. Bask1). GEN, Boston, MA: Pearson Education, Inc.

Griffiths, A. K., \& Grant, B. A. (1985). High school students' understanding of food webs: Identification of a learning hierarchy and related misconceptions. Journal of Research in Science Teaching, 22(5), 421-436. https://doi.org/10.1002/ tea.3660220505

Han S., Rosli R., Capraro M. M., \& Capraro R. M. (2016), The effect of science, technology, engineering and mathematics (STEM) project based learning (PBL) on students' achievement in four mathematics topics. Journal of Turkish Science Education, 13(Special issue), 3-30. https://doi.org/10.12973/ tused.10168a

Haris, N., \& Osman, K. (2015). The effectiveness of a virtual field trip (VFT) module in learning biology. Turkish Online Journal of Distance Education, 16(3), 102-117. Retrieved from https://files.eric.ed.gov/ fulltext/EJ1092841.pdf

Huri, N. H. D., \& Karpudewan, M. (2019). Evaluating the effectiveness of Integrated STEM-lab activities in improving secondary school students' understanding of electrolysis. Chemistry Education Research and Practice, 20(3), 495-508. https:/ / doi.org/10.1039/C9RP00021F

Jordan, R. C., Brooks, W. R., Hmelo-Silver, C., Eberbach, C., \& Sinha, S. (2014). Balancing broad ideas with context: An evaluation of student accuracy in describing ecosystem processes after a system-level intervention. Journal of Biological Education, 48(2), 57-62.

https:/ / doi.org/10.1080/00219266.2013.821080

Jordan, R., Gray, S., Demeter, M., Lui, L., \& HmeloSilver, C. (2009). An assessment of students' understanding of ecosystem concepts: Conflating ecological systems and cycles. Applied Environmental Education and Communication, 8(1), 40-48.

https:/ / doi.org/10.1080/15330150902953472

Jussila, T., \& Virtanen, V. (2014). Learning in Virtual Forest: A forest ecosystem in the web-based learning environment. Journal of Biological Education, 48(4), 196-200. https:/ / doi.org/10.1080/ 00219266.2013 .863794

Kelley, T. R., \& Knowles, J. G. (2016). A conceptual framework for integrated STEM education. International Journal of STEM Education, 3(1), 11. https:/ / doi.org/10.1186/s40594-016-0046-Z

Kinchin, I. M. (2010). Solving Cordelia's dilemma: Threshold concepts within a punctuated model of learning. Journal of Biological Education, 44(2), 53-57. https:// doi.org/10.1080/00219266.2010.9656194

Kuenzi, J. J. (2008). Science, technology, engineering, and mathematics (STEM) education: Background, federal policy, and legislative action. Retrieved from http:/ / digitalcommons.unl.edu/crsdocs/35

Lin, C. Y., \& Hu, R. (2003). Students' understanding of energy flow and matter cycling in the context of the food chain, photosynthesis, and respiration. International Journal of Science Education, 25(12), 1529-1544. https:/ / doi.org/10.1080/0950069032000052045

Lou, S. J., Chou, Y. C., Shih, R. C., \& Chung, C. C. (2017). A study of creativity in $\mathrm{CaC} 2$ steamship-derived STEM project-based learning. Eurasia Journal of Mathematics, Science and Technology Education, 13(6), 2387-2404.

https:/ / doi.org/10.12973/eurasia.2017.01231a

Moore T. J., Johnson C. C., Peters-Burton E. E. and Guzey S. S., (2016), The need for a stem road map, in Johnson C. C., Peters-Burton E. E., Moore T. J. and Selcen Guzey S. (ed.), STEM road map: a framework for integrated STEM education, NY: Routledge Taylor \& Francis Group. National, 1st edn, pp. 3-12.

Moore T. J., Stohlmann M. S., Wang H.-H., Tank K. M., Glancy A. W. and Roehrig G. H., (2014), Implementation and integration of engineering in 
K-12 STEM education. In S. Purzer, J. Strobel and M. Cardella (ed.), Engineering in precollege settings: research into practice, West Lafayette: Purdue Press, pp. 35-60.

Munson, B. H. (1994). Ecological misconceptions. Journal of Environmental Education, 25(4), 30-34. https:// doi.org/10.1080/00958964.1994.9941962

O'Bannon, B. W., Beard, J. L., \& Britt, V. G. (2013). Using a Facebook group as an educational tool: Effects on student achievement. Computers in the Schools, 30(3), 229-247.

https:// doi.org/10.1080/07380569.2013.805972

Özata-Yücel, E., \& Özkan, M. (2015). Determination of secondary school students' cognitive structure, and misconception in ecological concepts through word association test. Educational Research and Reviews, 10(5), 660-674. https://doi.org/10.5897/ ERR2014.2022

Özkan, Ö., Tekkaya, C., \& Geban, Ö. (2004). Facilitating conceptual change in students' understanding of ecological concepts. Journal of Science Education and Technology, 13(1), 95-105. https:/ / doi.org/10.1023/ B:JOST.0000019642.15673.a3

Pai, A., McGinnis, G., Bryant, D., Cole, M., Kovacs, J., Stovall, K., \& Lee, M. (2017). Using Facebook groups to encourage science discussions in a largeenrollment biology class. Journal of Educational Technology Systems, 46(1), 103-136. https://doi.org/10.1177/0047239516675898

Park, D. Y., Park, M. H., \& Bates, A. B. (2018). Exploring young children's understanding about the concept of volume through engineering design in a STEM activity: A case study. International Journal of Science and Mathematics Education, 16(2), 275-294. https:/ / doi.org/10.1007/s10763-016-9776-0

Pfundt H \& Duit R (2002) Bibliography: Student's alternative frameworks and science education. Kiel, Germany. Leibniz-Institute for Science Education (distributed electronically). Retrieved from http://www.eric.ed.gov/PDFS/ED342643.pdf

Prescott, J., Stodart, M., Becket, G., \& Wilson, S. (2013a). The experience of using Facebook as an educational tool. Health and Social Care Education, 1-5. https:// doi.org/10.11120/hsce.2013.00033

Prescott, J., Wilson, S., \& Becket, G. (2013b). Facebook use in the learning environment: do students want this?. Learning, Media and Technology, 38(3), 345-350. https:// doi.org/10.1080/17439884.2013.788027

Purwanti, E., \& Prihanta, W. (2016). Penguatan Literasi Ekosistem Pada Siswa Klas X Dengan Specific Materi: Pembelajaran Ekosistem Melalui Penelitian Ekofisiologi Hutan Mangrove. In Prosiding Seminar
Nasional dan Gelar Produk,155-163.Retrieved from http:/ / research-report.umm.ac.id/index.php/ research-report/article/view/767

Reiner, M., \& Eilam, B. (2001). Conceptual classroom environment-a system view of learning. International Journal of Science Education, 23(6), 551568. https:// doi.org/10.1080/095006901300172458

Sander, E., Jelemenská, P. A., \& Kattmann, U. (2006). Towards a better understanding of ecology. Journal of Biological Education, 40(3), 119-123. https:/ / doi.org/10.1080/00219266.2006.9656028

Setiawan, H., Isnaeni, W., Budijantoro, F. P. M. H., \& Marianti, A. (2015). Implementation of digital learning using interactive multimedia in excretory system with virtual laboratory. Research and Evaluation in Education, 1(2), 212-224. https:/ / doi.org/10.21831/reid.v1i2.6501

Shahali, E. H. M., Halim, L., Rasul, M. S., Osman, K., \& Zulkifeli, M. A. (2016). STEM learning through engineering design: Impact on middle secondary students' interest towards STEM. Eurasia Journal of Mathematics, Science and Technology Education, 13(5), 1189-1211.

https:/ / doi.org/10.12973/eurasia.2017.00667a

Sterman, J. D., \& Sweeney, L. B. (2007). Understanding public complacency about climate change: adults' mental models of climate change violate conservation of matter. Climatic Change, 80(3-4), 213-238. https://doi.org/10.1007/s10584-0069107-5

Suprapto, P. K., \& Supriatno, B. (2013). Meningkatkan Pengetahuan Struktur dan Fungsi Hutan melalui Model Field Trip Training (Ftt) Ekplorasi Hutan pada Mahasiswa Calon Guru Biologi. In Prosiding Seminar Biologi, 10(2), 152-158. Retrieved from https://jurnal.uns.ac.id/prosbi/article/viewFile/ 6530/5910

Waheed, T., \& Lucas, A. M. (1992). Understanding interrelated topics: photosynthesis at age photosynthesis at age14+. Journal of Biological Education, 26(3), 193-199. https:/ / doi.org/10.1080/ 00219266.1992 .9655272

Wyner, Y., \& Blatt, E. (2019). Connecting ecology to daily life: how students and teachers relate food webs to the food they eat. Journal of Biological Education, 53(2), 128-149. https://doi.org/10.1080/00219266. 2018.1447005

Yorek, N., Ugulu, I., Sahin, M., \& Dogan, Y. (2010). A qualitative investigation of students' understanding about ecosystem and its components. Natura Montenegrina, 9(3), 973-981.

\section{http://www.ejmste.com}

